\title{
Aoristo)))))
}

International Journal of Phenomenology, Hermeneutics and Metaphysics

\section{Do Lebenswelt ao Dasein: condições filosóficas para o método fenomenológico}

\author{
From Lebenswelt to Dasein: philosophical conditions for \\ the phenomenological method \\ Drnda. Luciane Luisa Lindenmeyer \\ Universidade do Vale dos Sinos-Unísinos'
}

\section{RESUMO}

Este artigo aborda as correspondências e distinções entre as noções de Lebenswelt husserliana e de Dasein heideggeriana a fim de destacar as condições conceituais para uma caracterização do método especificamente fenomenológico. O Lebenswelt, ou mundo da vida, corresponde à dimensão cultural e histórica da vida, onde as subjetividades são constituídas intersubjetivamente. O Dasein, por sua vez, refere-se à condição de ser-no-mundo que compõe a existência de todo indivíduo. É a partir da nossa capacidade de autorreflexão, de ponderação sobre nossa condição de presença no mundo que nossa existência adquire singularidade em relação aos outros entes. Neste estudo comparativo entre essas duas noções de projetos fenomenológicos, em grande medida, destoantes, apresentamos suas distinções e equivalências como caracteres do método fenomenológico por excelência.

\section{PALAVRAS-CHAVE}

Lebenswelt; Dasein; Fenomenologia; Husserl; Heidegger

\section{ABSTRACT}

This article deals with correspondences and distinctions between the notions of Lebenswelt Husserlian and Dasein Heideggerian with the purpose of highlighting as conceptual conditions for a characterization of the phenomenological method. Lebenswelt, or world of life, corresponds to the cultural and historical dimension of life, where subjectivities are constituted intersubjectively. Dasein, in turn, refers to the condition of being no world that makes up the presence of every individual. It is from our capacity for self-reflection, the consideration of our condition of presence in the world and our presence to acquire uniqueness in relation to other beings. In this comparative study of these two

\footnotetext{
${ }^{1}$ E-mail: lucianelindenmeyer@gmail.com
} 


\section{Aoristo)))))}

International Journal of Phenomenology, Hermeneutics and Metaphysics

notions of largely unfolding phenomenological projects, we present their distinctions and equivalences as characters of the phenomenological method par excellence.

\section{KEYWORDS}

Lebenswelt; Dasein; Phenomenology; Husserl; Heidegger

\section{INTRODUÇÃO}

A fenomenologia é fundada por Edmund Husserl na virada do século XIX para o XX. Sua origem teórica está diretamente ligada à crítica ao positivismo e ao psicologismo ${ }^{2}$. Isso significa que a fenomenologia, como ciência dos fenômenos enquanto aparecimentos ou manifestações para a consciência, não incorre em um método explicativo da realidade que reduz o mundo circundante às análises materiais e tampouco considera apenas as manifestações psicológicas e subjetivas. A orientação fenomenológica é aquela que vincula sujeito e objeto, consciência e mundo em uma relação de indissociabilidade. Nesse contexto, o conceito que adquire centralidade filosófica é o de intencionalidade, com o qual a consciência é sempre pensada como direcionada para os objetos e outras subjetividades que compõem o mundo circundante ou transcendente.

A crítica fundacional de Husserl ao positivismo passa pelo apontamento das insuficiências da matematização contida no método científico, uma vez realizada a transposição de suas asserções para o mundo da vida, como mundo de cultura, de valores e de criatividade. A objetividade científica e o uso de um modelo explicativo do reducionismo materialista não dá conta, portanto, de compreender o mundo na sua dinâmica histórica e filosófica. Assim, a fenomenologia contém em si um novo formato de aproximação do sujeito em relação à realidade. Essa relação, em verdade, já está dada antes mesmo que possamos fazer juízos sobre o mundo. É nesse contexto de proposta de uma aproximação da realidade diversa daquela proposta pelas ciências naturais que podemos compreender a especificidade de conceitos como o Lebenswelt, ou o mundo da vida husserliano, e o Dasein heideggeriano, como condição préreflexiva da existência no mundo.

A partir desse contexto teórico, o propósito deste texto é, num primeiro momento, caracterizar essas duas noções de Lebenswelt e Dasein a partir das especificidades das propostas fenomenológicas de Husserl e de Heidegger, respeitando as suas divergências. No segundo momento, apresentaremos as condições

\footnotetext{
2 Existem diversos tipos de psicologismo: o lógico, o epistemológico, o moral, o semântico. Husserl estava preocupado com os dois primeiros. Em termos lógicos, a fenomenologia, como ciência de rigor, seria controversa ao partir da premissa de que os conteúdos lógicos existem apenas na consciência do sujeito que pensa sobre eles. Essa proposição incorre também em problemas epistemológicos, na medida em que o conhecimento acerca do mundo estará comprometido unicamente com o pensamento subjetivo. A crise epistemológica que Husserl pretende superar com a nova orientação fenomenológica de seu pensamento diz respeito à clássica dicotomia filosófica entre realismo e idealismo. $\mathrm{O}$ aparecimento dos fenômenos para a consciência intencional não está no nível dos objetos puros das ciências naturais.
} 


\section{Aoristo)))))}

International Journal of Phenomenology, Hermeneutics and Metaphysics

filosóficas desses dois termos, centrais para os estudos da fenomenologia em geral, para a fundamentação do método especificamente fenomenológico, enquanto modelo de aproximação com a realidade e o mundo da vida. Tanto o mundo da vida husserliano quanto o ser-aí no mundo heideggeriano são constituídos filosoficamente a partir da relação entre subjetividade e mundo circundante.

A nova orientação fenomenológica proposta desde sua origem como segmento filosófico não pressupõe a análise dos objetos puros que são explorados pelo materialismo reducionista das ciências naturais através do uso do seu método empírico. Nesse sentido, nem mesmo o mundo da vida adquire esse sentido. Sua caracterização não é a de um objeto a ser explorado fenomenologicamente a fim de que dele sejam extraídos os elementos que compõem a sua estrutura físico-química. $\mathrm{O}$ mundo da vida "se opõe a todo objetivismo" (GADAMER, 1997, p. 375), justamente porque ele faz referência, primeiramente, a "uma vida cuja atividade possui fins" (HUSSERL, 2008, p. 61) e ao "todo em que estamos vivendo enquanto seres históricos" (GADAMER, 1997, p. 375). A perspectiva histórico-cultural, como sendo uma perspectiva não estática, não pode ser reduzida à análise matemática tão cara às ciências naturais. Sua orientação é completamente outra, aquela que está às voltas com a criatividade e com o estabelecimento de valores compartilhados socialmente.

\section{LEBENSWELT COMO MUNDO PARA TODOS}

O conceito de mundo da vida (Lebenswelt) é introduzido por Husserl, no período final de suas produções, na sua obra A Crise da humanidade europeia e a filosofia. Sua análise filosófica nesse período passa a explorar a dimensão das experiências de consciência na sua dimensão compartilhada. $O$ mundo da vida é pensado não apenas em nível natural, mas também na dimensão que caracteriza a orientação propriamente fenomenológica, isto é, a transcendental. O modelo de idealismo transcendental atribuído por Husserl à fenomenologia é composto pela subjetividade e pela intersubjetividade, na medida em que reconhecemos a existência corporificada das demais consciências e atribuímos a estas valores diferentes aos que associamos aos demais objetos que integram o mundo da vida.

É pela dimensão da intersubjetividade, ou do reconhecimento da existência das outras consciências que podemos considerar que a fenomenologia não é uma equivalente ipsis litteris do pensamento cartesiano. Para que não haja confusão, é necessária a compreensão da noção que é central para o pensamento husserliano, a de redução fenomenológica. É pela redução que passamos da orientação natural do mundo para a sua orientação propriamente fenomenológica. Para que a redução seja de fato realizável é preciso que voltemos à subjetividade. Ainda assim, a proposta de Husserl é a de que o retorno à subjetividade transcendental resulte em uma "Fenomenologia da intersubjetividade transcendental e, por seu intermédio, se desenvolva numa Filosofia Transcendental em geral" (HUSSERL, 2013, p. 68). O mundo da vida está justamente situado nessa dimensão transcendental que caracteriza a análise fenomenológica. 


\section{Aoristo)))))}

\section{International Journal of Phenomenology, Hermeneutics and Metaphysics}

Embora a subjetividade seja central para a fenomenologia, é no mundo que está “[...] o conjunto completo dos objetos da experiência possível e do conhecimento possível da experiência" (HUSSERL, 2006. §1. p. 34). A partir do mundo da vida compreendemos a vida consciente como vida coletiva na qual o ego encontra o alterego através de uma relação de mútuo reconhecimento, sem, no entanto, confundirem-se. Em nível transcendental, o mundo da vida antecede a consciência que intenciona os objetos e os outros indivíduos. Ele existe antes da formulação de juízos sobre ele e mesmo da justificação do conhecimento acerca de sua configuração natural. Dessa forma, fica claro que o conceito de vida não é para Husserl a caracterização biológica da existência, visto que ela é justamente a "crítica da ingenuidade objetivista de toda filosofia precedente. Aos seus olhos, ela consiste em haver revelado a controvérsia aparente entre idealismo e realismo" (GADAMER, 1997, p. 377).

No contexto da fenomenologia de Husserl, os objetos de interesse investigativo são os objetos correlatos, ou objetos intencionais, que se referem às estruturas da própria consciência, que está sempre em relação a alguma coisa que está no mundo. A subjetividade não é, nesse sentido, oposta à objetividade como os dualismos que antecederam a fenomenologia de consciência-mundo, idealismo-realismo, pressupunham. Só podemos pensar nas proposições da fenomenologia a partir dessa correlação de intencionalidade entre consciência e o mundo da vida, onde nosso próprio ego está inserido e que abriga também o alterego ou as outras subjetividades. Dessa maneira, a intersubjetividade equivale a um "tipo de intencionalidade que age em nossa experiência de outras pessoas" (SOKOLOWISKI, 2012, p. 157). Nossas vivências de consciência são sempre centralizadas a partir de nosso ego, que é o resíduo fenomenológico da nossa relação com o mundo e com o outro. No entanto, essas vivências estão sempre situadas no mundo em que estamos inseridos. É nele que está o horizonte presente de nossas experiências.

O mundo da vida não é um mundo apresentado fenomenologicamente como sendo totalmente oposto ao mundo natural, uma vez que ele é, em verdade, o ponto de partida para o método científico, e não o contrário. Nesse preciso sentido,

Não poderíamos viver no mundo projetado pela ciência; somente podemos viver no mundo-da-vida, e esse mundo básico tem suas formas próprias de verdade e verificação que não são deslocadas, mas apenas complementadas pela verdade e pela verificação introduzidas pela ciência moderna (SOKOLOWISKI, 2012, p. 159).

É no mundo da vida circundante que são presentificadas as nossas experiências imediatas que são os objetos de grande interesse para a fenomenologia. Essas experiências imediatas referem-se ao aparecimento pré-reflexivo dos fenômenos. $\mathrm{O}$ mundo da vida está, nesse sentido, contido em nossas experiências conscientes mesmo antes de que façamos juízos sobre ele. As coisas se manifestam para a consciência a partir de seus modos próprios de doação. Um livro já se mostra como um livro, uma caneta já é uma caneta, antes de explicarmos a sua constituição físico-química ou as realizações mentais que temos ao experienciarmos esses objetos. São esses 


\title{
Aoristo)))))
}

\section{International Journal of Phenomenology, Hermeneutics and Metaphysics}

aparecimentos imediatos que não podem ser completamente naturalizados ou explicados unicamente por sua composição material.

Os objetos e pessoas que constituem o mundo da vida estão aí para mim. As experiências conscientes subjetivas, isto é, as experiências em primeira pessoa, são o ponto de partida para a análise fenomenológica do mundo. Sua estrutura material, reivindicada pelas ciências naturais, está suspensa na orientação fenomenológica. Nesse sentido, os modos de aparecimento dos objetos intencionais não pressupõem unicamente a constituição corpórea do objeto, mas sim a perspectiva em que nos encontramos quando experienciamos as coisas. Essas experiências imediatas, situadas no mundo da vida, compõem o próprio horizonte das demais ciências. O contrário não corresponde às nossas próprias experiências imediatas, ou seja, não vislumbramos todos os elementos físico-químicos que constituem as coisas e nós mesmos enquanto estamos já inseridos no mundo e experienciando espontaneamente tudo o que o compõe.

Para que possamos perceber o mundo pela sua dimensão fenomenológica da vida que, por ser imediata, é anterior à objetividade da ciência, faz-se necessária a redução fenomenológica ou a suspensão do mundo natural. É apenas dessa maneira que temos acesso ao mundo como fenômeno, ou ainda, enquanto "coisa mesma". Nesse contexto teórico, o mundo da vida é a própria estrutura implícita nesse processo de intencionalidade que constitui a relação consciência-mundo. Destarte, é no mundo da vida que estão as unidades de sentido que partem da consciência, de maneira que

\begin{abstract}
Uma intencionalidade operante age e é agida, e onde só por um esforço de retomada deste vivido, o sentido se esclarece em diferentes níveis de constituição, um dos quais é o pensar reflexivo. A estrutura de relação subjacente a uma relação de conhecimento é aquela que nos propicia falar de um sujeito pensante que, num momento posterior àquele em que vive como ser-no-mundo, se pergunta: 'Quem sou eu que vivo"? (DICHTCHEKENIAN, 1984, p. 30).
\end{abstract}

É imprescindível, assim, o retorno ao mundo da vida para que a fenomenologia seja, de fato, uma ciência de rigor. A subjetividade é um elemento importante para o modelo de idealismo transcendental ao qual Husserl atribui equivalência para a sua fenomenologia. No entanto, essa modalidade de idealismo não isola essa subjetividade em relação ao mundo. A subjetividade transcendental que daí decorre contém em si mesma o mundo da vida, ou o mundo transcendente.

Ao reintegrar a subjetividade ao mundo da vida, Husserl demonstra as insuficiências do método cartesiano, que possuía ainda uma forte orientação naturalista não considerando a condição de mundaneidade, ou de ser-no-mundo, da própria existência. O completo isolamento da consciência, na sua própria racionalidade, em relação ao mundo proposto por Descartes como fonte segura para o conhecimento incorre em um erro bastante significativo, na medida em que 


\section{Aoristo)))))}

International Journal of Phenomenology, Hermeneutics and Metaphysics

[...] se o visualizar-me como ser racional impede o reconhecimento de outros aspectos com os quais convivo originalmente, ou os anula, e me leva, ao contrário, à ilusão de posse definitiva de mim por mim mesmo, então a barreira entre vivido e o conceitual torna-se intransponível e, com isso se chega à descrença no próprio conhecimento (DICHTCHEKENIAN, 1984, p. 30).

A crítica husserliana ao modelo de solipsismo cartesiano possibilita a abertura para a autorreflexão que caracteriza o pensamento fenomenológico, em especial, na concepção do Dasein heideggeriano enquanto dimensão de ser-no-mundo. É na medida em que reconhecemos o caráter de mundaneidade da existência, o que não seria possível na insistência de uma dicotomia entre sujeito e mundo, que se inicia a reflexão sobre essa condição em que estamos inseridos.

\section{O DASEIN COMO O ESTAR PRESENTE NO MUNDO}

A fenomenologia adquire uma roupagem original sob o olhar heideggeriano. Seu projeto filosófico, versado na história da filosofia, é influenciado não apenas pela fenomenologia de Husserl, de quem Heidegger fora aluno, mas também pela filosofia pré-socrática, com a qual ele trata da noção de verdade que caracteriza o seu projeto de uma fenomenologia ontológica. Ainda que ele reconheça que "o método fenomenológico, no entanto, permanecerá altamente questionável caso se queira recorrer às ontologias historicamente dadas ou a tentativas congêneres" (HEIDEGGER, 2005, p. 56).

Esse reconhecimento é bastante significativo, uma vez que o próprio Husserl rejeitava a comparação entre fenomenologia e ontologia. Uma abordagem filosófica que considere esses dois campos como equivalentes está equivocada. Certamente, como vimos, Heidegger sabia disso e seu afastamento da fenomenologia "originária" de seu mestre não se deu por uma incompreensão de suas proposições, mas sim porque Heidegger pensava em estabelecer o seu projeto filosófico pessoal, para o qual a fenomenologia, mesmo com a dedicatória a Husserl nas primeiras páginas de Ser e Tempo, era apenas uma de suas fontes de trabalho.

O método fenomenológico é aplicado por Heidegger como um dos elementos de sua ontologia fundamental, estritamente vinculada à sua analítica existencial, com as quais ele pretendia corrigir o abandono da problemática do ser, conforme o modelo pré-socrático, ao longo da história da filosofia e da metafísica. A fenomenologia, como aproximação do real pautada pela volta às coisas mesmas, mas para Heidegger sem a redução fenomenológica, elemento rejeitado por ele, e pela manifestação do que se mostra enquanto si mesmo para a subjetividade é um caminho filosófico para que o indivíduo reflita sobre as especificidades de seu próprio modo de ser no mundo em relação aos demais entes que compõem o mundo circundante.

Heidegger rejeitou juntamente com a noção de redução fenomenológica a própria formulação da fenomenologia como uma ciência "pura". Essa rejeição situa Heidegger, mesmo que a contragosto pessoal, na tradição de fenomenólogos conhecidos como "existenciais" (CERBONE, 2012, p. 62), justamente em contraposição 


\section{Aoristo)))))}

International Journal of Phenomenology, Hermeneutics and Metaphysics

aos fenomenólogos "puros" (CERBONE, 2012, p. 62), adeptos da noção de redução fenomenológica elaborada por Husserl. O Dasein heideggeriano é incompatível com as pretensões husserlianas de suspensão da atitude natural. Nossas experiências empíricas da realidade são por demais espontâneas para que a redução fenomenológica seja de fato realizável.

Dadas as divergências, tanto Husserl quanto Heidegger estavam de acordo sobre a definição da fenomenologia como método. Seja quando Husserl considera que “ [...] terei manifestamente como primeira questão refletir sobre como poderei encontrar um método de progressão, que possa conduzir-me ao saber autêntico" (HUSSERL, 2013, p. 40). Seja quando Heidegger (2005, p. 57) afirma claramente que "A expressão 'fenomenologia' diz, antes de tudo, um conceito de método". O ponto de divergência entre eles está no aparato conceitual e no enfoque filosófico necessários para tal empreendimento. Husserl considera que a fenomenologia não abarca os mesmos objetos que as ciências empíricas, ou seja, os objetos puros. Esses objetos dependentes da análise empírica estariam presentes também no clássico embate filosófico entre realismo e idealismo, visto que em ambas as vertentes, a existência material das coisas é um pressuposto. Mesmo a ontologia estaria implicada na existência desses objetos puros, na medida em que propõe a apreensão do ser dos entes.

Como vimos no tópico anterior, a preocupação filosófica que funda a fenomenologia não é a de abordar exclusivamente o problema do ser, mas sim analisar os objetos correlatos, ou ainda, a relação intencional entre consciência e mundo pela perspectiva do problema do conhecimento. O enfoque de Heidegger no contexto do seu pensamento fenomenológico destoante e original perpassa a noção do Dasein, a partir da qual ele propõe a análise dos fenômenos. Na acepção Heideggeriana fenômeno é, de maneira semelhante ao que considera Husserl, "[...] o que se revela, o que se mostra a si mesmo" (HEIDEGGER, 2005, p. 58), ou ainda, "[...] como o que se mostra, e fenômeno como aparecer, parecer e aparência" (HEIDEGGER, 2005. §7. p. 58). Essas afirmações corroboram a proposta filosófica de Heidegger de estabelecer a sua ontologia fundamental para explorar a dimensão do ser, de modo geral, através do conceito de Dasein como o ser-no-mundo. Nesse sentido,

O ser do Dasein está lançado no mundo, projectado a frente de si mesmo para ser o que pode ser. Neste estado de estar lançado, de completo abandono, ele sente que é o seu ser que está em causa. (PASQUA, 1993, p. 95).

Ao considerar o método fenomenológico como base para a sua ontologia fundamental, mas com uma nova interpretação de suas proposições, o Ser que é objeto de interesse da fenomenologia ontológica de Heidegger está diretamente vinculado à nossa presença no mundo. $\mathrm{O}$ abandono que se segue dessa presença corresponde ao ser-aí, na medida em que somos lançados na mundaneidade e na realidade. Ainda assim, o Ser, na fenomenologia de Heidegger "[...] é sempre qualquer coisa, é poder ser, é poder ser do ente" (PASQUA, 1993, p. 96). Esse poder ser, essa abertura para a 


\section{Aoristo)))))}

\section{International Journal of Phenomenology, Hermeneutics and Metaphysics}

possibilidade situada no futuro está ligada à noção de verdade como alétheia e do seu sentido de desvelamento, aos moldes pré-socráticos, e não mais como uma modalidade de verdade por adequação ou correspondência. O Dasein como um poder ser funciona como um elemento pré-ontológico para o desvelamento da verdade ou o sentido desse Ser, enquanto presença no mundo.

Heidegger rejeita a noção, segundo ele, "vaga e mediana", do ser como uma simples ligação entre sujeito e predicado, o que incorre em "um mero conhecimento verbal" (HEIDEGGER, 2005, p. 31). O propósito original de seu pensamento em relação ao problema do Ser está relacionado como a questão do Ser em geral. Nesse sentido, ele também pretende reformular a ontologia a partir de uma análise semelhante aos apontamentos husserlianos sobre as insuficiências da ontologia clássica como componente fenomenológico, na medida em que se faz necessário que o Ser em geral também seja o fio condutor da ontologia e não apenas o ser dos entes individuais.

A aproximação da realidade pelo modelo fenomenológico heideggeriano é realizada não mais pela noção de consciência, como para Husserl, uma vez que seu método é, agora, voltado para a compreensão do ser "com a investigação do Dasein em si mesmo e por si mesmo" (NUNES, 2002, p. 12). Nesse sentido, só podemos considerar a sua analítica da existência na medida em que a centralidade da presença e do ser-aíno-mundo esteja clarificada. A importância desse elemento filosófico está no modo como o Dasein caracteriza todos os entes. Assim, o Dasein compreende o próprio ser a partir possibilidades como ser e mesmo como um não-ser.

Ao Dasein, como ser-no-mundo, corresponde o ente que o próprio indivíduo é enquanto sujeito. A partir da autorreflexão que resulta da presença no mundo "se estabelece uma relação circular entre quem questiona e o questionado, entre quem interroga, o ente que somos e o ser interrogado" (NUNES, 2002, p. 11). A precursora aproximação da realidade proposta pelo pensamento fenomenológico, em detrimento da abordagem cientificista do mundo da vida, realizada a partir da análise das próprias vivências de consciência possibilita a volta às coisas mesmas enquanto o mundo da vida seja tomado através do seu aparecimento para a consciência. Essa aproximação fenomenológica do sujeito com o mundo tem como pano de fundo a posição de que "A ciência não tem e não terá jamais o mesmo sentido de ser que o mundo percebido, pela simples razão de que ela é uma determinação ou uma explicação dele" (MERLEAU-PONTY, 1999, p. 3).

\section{CONSIDERAÇÕES FINAIS}

Como vimos, a fenomenologia surge nas antípodas do naturalismo e do psicologismo. Sua nova orientação reintegra o sujeito ao mundo, ou a consciência ao conhecimento, de maneira indissociável. Como resultado desse processo, a fenomenologia, enquanto campo filosófico, analisa a própria relação existente entre todos esses elementos e não as suas caracterizações individuais. O ponto de partida são, assim, as experiências imediatas que a consciência tem do mundo como fenômeno a partir dos diferentes modos de doação e aparecimento das coisas. 


\section{Aoristo)))))}

International Journal of Phenomenology, Hermeneutics and Metaphysics

É no contexto do mundo da vida compartilhado, ou do Lebenswelt, e do Dasein heideggeriano, como elemento filosófico que indica o ser-aí ou a presença no mundo, que são realizadas as experiências originárias de sentido. Essas duas concepções indicam igualmente e ao seu modo a posição antinaturalista implícita no método fenomenológico como método especificamente filosófico. O Lebenswelt husserliano e o Dasein heideggeriano como análise filosófica que tem como ponto de partida a própria presença no mundo são elementos que caracterizam a fenomenologia, no sentido de que todo o conhecimento científico é posterior ao mundo vivido.

Nossas experiências imediatas, em primeira pessoa, são anteriores ao conhecimento das ciências naturais. Nesse sentido, a explicação naturalista da realidade só adquire sentido, na medida em que ela esteja interligada com essas experiências imediatas. Nossas experiências cotidianas não abarcam as explicações abstratas e grandes generalizações científicas como fenômeno. É desse modo que a fenomenologia, como campo filosófico, reivindica para si o nível das aparências. Sem menosprezar a importância das ciências empíricas, a fenomenologia, como vimos, sob nova orientação, analisa aquilo o que aparece e não a composição físico-química do mundo.

Diante da orientação propriamente fenomenológica, tanto Husserl na formulação do conceito de Lebenswelt, quanto Heidegger e a sua noção de Dasein, tinham a preocupação com a distinção entre os indivíduos e os objetos ordinários. A nossa existência consciente atuante em todas as nossas vivências de mundo é também o elemento que nos distancia da existência irrefletida dos demais elementos que compõem o mundo da vida. A condição que distancia a nossa existência dos outros entes é justamente o Dasein, como ser-aí, como ser-no-mundo. É a partir da nossa capacidade de autorreflexão, de ponderação sobre nossa condição de presença no mundo que nossa existência adquire singularidade em relação aos outros entes.

O pensamento fenomenológico tem como uma de suas principais premissas a ideia de que o sentido ou o significado tem a sua constituição nas nossas experiências de consciência vinculadas ao mundo. É a partir das noções de Lebenswelt e de Dasein, dadas as suas especificidades, que a fenomenologia problematiza filosoficamente o mundo a partir de uma relação direta com a nossa própria existência. Essa relação é necessária para a compreensão da dimensão histórica e cultural da vida, assim como está igualmente implícita nos questionamentos heideggerianos acerca do que significa de fato, para qualquer coisa, o ser.

A ontologia proposta por Heidegger corresponde, para além do paradigma présocrático de verdade, ao modelo de uma fenomenologia fundamental. No contexto do seu pensamento, a problemática resultante das questões filosóficas vinculadas à presença no mundo é estendida, a partir do método fenomenológico, para abranger o problema do ser numa relação universalizável do sujeito com o mundo. É a inescrutável presença no mundo que é perquirida enquanto fenômeno que antecede até mesmo a compreensão sobre esse ser-no-mundo. Num sentido husserliano, já estamos inseridos no mundo antes mesmo que façamos juízos sobre ele e antes de que possamos tematizá-lo. 


\section{Aoristo)))))}

International Journal of Phenomenology, Hermeneutics and Metaphysics

Os diferentes modos de doação que caracterizam os fenômenos que se manifestam para a consciência só podem ser reflexionados através do reconhecimento de nossa presença no mundo. A compreensão desses modos de ser que são manifestos para a consciência estão condicionados aos entes que compõem o mundo. Ao fundar o seu pensamento no método fenomenológico, mas ao mesmo tempo rejeitando a noção de redução fenomenológica, Heidegger apresenta uma fenomenologia das experiências cotidianas muito mais espontânea do que Husserl, isto é, nossa presença no mundo e mesmo a atitude natural que é dela resultante, não pode, de fato ser suspendida se nossa relação com o mundo é intencionalmente indissociável dele.

A nova proposta de aproximação da realidade presente no pensamento fenomenológico corresponde à centralização do mundo da vida pré-científico que já está dado em detrimento das formulações abstratas que acompanham a abordagem do mundo pelo viés puramente científico. Afinal, a fenomenologia, ao não ter como interesse os mesmos objetos dissecados pela positividade científica, "O discurso filosófico não deverá ser comandado pelas regras que comandam o discurso científico" (MOURA, 1989, p. 25). É exatamente nesse sentido que o método fenomenológico equivale ao método especificamente filosófico fundado em nossas experiências imediatas e cotidianas.

O filosofar através do método fenomenológico corresponde, portanto, à superação da atitude natural acompanhada de um retorno à subjetividade consciente, para Husserl, e às atividades da cotidianidade, para Heidegger. Nesse sentido, não é possível erigirmos o conhecimento filosófico ou as estruturas de inteligibilidade do mundo sem levar em conta as manifestações do mundo no contexto de nossas próprias vidas cotidianas e atividades diárias.

A cotidianidade do mundo é composta a partir da relação de nossas subjetividades com os objetos de uso e com as outras subjetividades que estão aí como entidades que se mostram para mim, cada qual por um modo específico de manifestação. É nessa dimensão do mundo enquanto fenômeno manifesto para nós que o método fenomenológico apresenta um novo modelo de aproximação filosófica com a realidade através da qual são instituídos os sentidos e significados que compõem a nossa própria existência no mundo.

\section{REFERÊNCIAS}

CERBONE, D. R. Fenomenologia. Trad. Caesar Souza. Petrópolis: Vozes, 2012.

DICHTCHEKENIAN, M. F. O cogito e o mundo da vida - proposta de um fundamento rigoroso para o conhecimento. In: DICHTCHEKENIAN, Maria Fernanda S. Farinha Beirão; MARTINS, Joel (Org.). Temas fundamentais da fenomenologia. São Paulo: Editora Moraes, 1984.

GADAMER, H.-G. Verdade e Método: traços fundamentais de uma hermenêutica filosófica. Trad. Flávio Paulo Meurer. Petrópolis: Vozes, 1997.

HEIDEGGER, M Ser e Tempo. Parte I. Trad. Marcia Sá Cavalcante Schuback. Petrópolis: Vozes, 2005. HUSSERL, E. A crise da humanidade europeia e a filosofia. Trad. Urbano Zilles. 3a Ed. Porto Alegre: EDIPUCRS, 2008.

. Ideias para uma fenomenologia pura e para uma filosofia fenomenológica: introdução geral à fenomenologia pura. Trad. Márcio Suzuki. Aparecida SP: Ideias e letras, 2006. 


\section{Aoristo)))))}

International Journal of Phenomenology, Hermeneutics and Metaphysics

. Meditações cartesianas e Conferências de Paris: de acordo com a Husserliana I. Trad. Pedro M. Alves. 1a Ed. Rio de Janeiro: Forense, 2013.

MERLEAU-PONTY, Maurice. Fenomenologia da percepção. Trad. Carlos Alberto Ribeiro de Moura. 2. a Ed. São Paulo: Martins Fontes, 1999.

MOURA, C. A. R. de. A crítica da razão na fenomenologia. São Paulo: Nova Stella, 1989.

NUNES, B. Heidegger e Ser \& Tempo. Rio de Janeiro: Jorge Zahar Ed., 2002.

PASQUA, H. Introdução à leitura de Ser e Tempo de Martin Heidegger. Lisboa: Instituto Piaget, 1993. SOKOLOWSKI, R. Introdução à fenomenologia. Trad. Alfredo de Oliveira Moraes. 3a Ed. São Paulo:

Edições Loyola, 2012.

Submetido: 6 de fevereiro de 2021

Aceíto: 5 de março de 2021 